\title{
Psychiatry and the Necker Cube. Neurological and Psychological Conceptions of Psychiatric Disorder
}

\section{ROGERS}

Burden Neurological Hospital, Stoke Lane, Stapleton, Bristol, BS16 1QT, England

\begin{abstract}
Neurological and psychological conceptions of psychiatric disorder are in conflict at the present time. This conflict is considered in the context of the history of psychiatry and the philosophy of science. Its practical consequences are considered for the motor disorder of schizophrenia, the cognitive impairment in psychiatric illnesses, the use of the terms organic and functional and the association of neurological disorder with psychotic and neurotic disorders. The conflict is also examined in individual cases and the implications for treatment assessed.
\end{abstract}

In recent articles by psychologists, neurologists and psychiatrists (Brown et al., 1984; Berrios, 1987), discussing the affective disorder of patients with neurological disease, it remains conventional to suggest that the mood disturbance may result from either a putative neurophysiological dysfunction or from a psychological reaction to the burden of the physical symptoms. If one thinks about it carefully, one sees that this alternative, neurophysiological dysfunction or psychological reaction, represents different ways of viewing the same disorder rather than distinguishing two different disorders. Neurophysiological and psychological conceptualizations of psychiatric disorder can be viewed, in terms of the philosophy of science, as paradigms as described by Thomas Kuhn (1970). These are different ways of making overall sense of the phenomena in a particular field of science. Examples in physics would be the Newtonian and Einsteinian way of conceptualizing the physical world. At any point in time, there is usually a particular paradigm that is favoured by most workers in that field. This could be called the prevailing paradigm for the time. However, at certain times, rival paradigms compete, with different workers favouring one or the other. What they cannot do is to favour two rival paradigms at the same time. An analogy can be made with the two different views of the Necker Cube. These are both valid but mutually exclusive ways of looking at the same cube. Psychiatric disorder can equally be viewed in two valid but different ways. These could be called the "neurological" and "psychological" paradigms of psychiatric disorder (Fig. 1). They are exemplified by the alternative explanations of mood disorder quoted above.

Unlike the paradigms in physics mentioned above, these two paradigms in psychiatry have switched back and forth in prevalence over the last hundred years. At the end of the last century, the prevailing paradigm $0953-4180 / 88 / 010003+08 \$ 3.50 / 0$ 


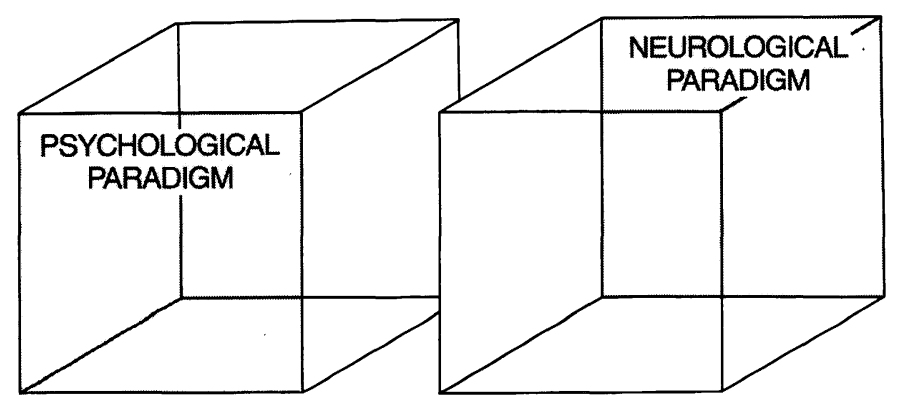

FIG. 1. Psychological and neurological conceptions of psychiatric disorder-two legitimate but incompatible views of the same disorder.

was neurological. In 1873 for example, Henry Maudsley wrote, "so far as the phenomena of deranged minds reach, the battle has been won and the victory is complete; no-one whose opinion is of any value pretends now that they are anything more than the deranged functions of the supreme nervous centres of the body". Between 1880 and 1910 however, the prevalent paradigm in psychiatry became a psychological one, concerned with abnormal mental states divorced from cerebral function. In 1932, in his presidential address to the psychiatry section of the Royal Society of Medicine, Bernard Hart wrote, "Mental disorder is being attacked along a number of different avenues, which fall into two broad groups, on the one hand the psychological and on the other, what we will term the physiological ... This second group ... follows the road of objective science ... The psychological group follows a road which is radically distinct, in that it seems to construct causal explanations out of the stuff of subjective experience ... The psychologist can claim that his method ... has at the present time indubitably achieved greater success than any other method ..." This remained the case until the 1950s when, for example, in the United States almost every professor of psychiatry was a psychoanalyst (Pichot, 1983). Over the last 20 years, the neurological paradigm has been re-establishing itself (Rogers, $1987 a$.

This conflict of paradigms, or alternative views of the Necker Cube, is well shown by the motor disorders of severe psychiatric illness (Rogers, 1985). For Kahlbaum, who described these disorders as catatonia in the last century, they represented disease of the brain. Kraepelin included catatonia among the group of deteriorating psychoses which he called dementia praecox. Bleuler, inspired by the ideas of Freud, renamed dementia praecox, schizophrenia. For Bleuler, all motor symptoms of schizophrenia were dependent on psychic factors for their origins. Schnautzkrampf or spasm of the perioral muscles, for example, was to be understood as an expression of contempt rather than as a localized tonic muscular contraction. Thereafter, catatonia became predominantly a disorder of the will and no longer one of the motor apparatus (Arieti, 1972). A separate vocabulary was developed to describe its features, and this makes it difficult now to be sure exactly how different these were to features found in recognized neurological disorder, 
except by comparing illustrations in contemporary psychiatric and neurological text books (Fig. 2). The appearance of symptoms "till the present time known only as functional symptoms of psychosis and psychogenic conditions" (Economo, 1931) following epidemic encephalitis caused quite a few authors in the 1920s to look at schizophrenia and its motor disorders from a neurological perspective. This, however, was not in keeping with the prevailing psychological paradigm and made little impact. When the psychodynamic interpretation of motor disorder became a spent force, alternative contributory causes to the motor disorder which did not threaten the psychological paradigm, such as institutionalization and neuroleptic medication in the 1950s and 1960s, were preferred. When Hans Steck, who had previously published what is still the most extensive study of extrapyramidal disorder in psychiatric illnesses $(1926,1927)$, became the first to describe neuroleptic induced Parkinsonism (1954), he suggested that neuroleptic medication in patients with schizophrenia was modifying the diseasebased motor disorder, but this suggestion was largely ignored. When, in the 1960s, drug-induced tardive dyskinesia was first described, there was initial resistance to its acceptance because of its similarity to disease-based motor disorder (Earl, 1983). Subsequently, however, motor disorder in patients with chronic schizophrenia was almost invariably attributed to their medication, so much so that, when equivalent motor disorders were described in patients apparently never treated with neuroleptic medication (Owens et al., 1982), this was ascribed by others to covert administration of the drugs.
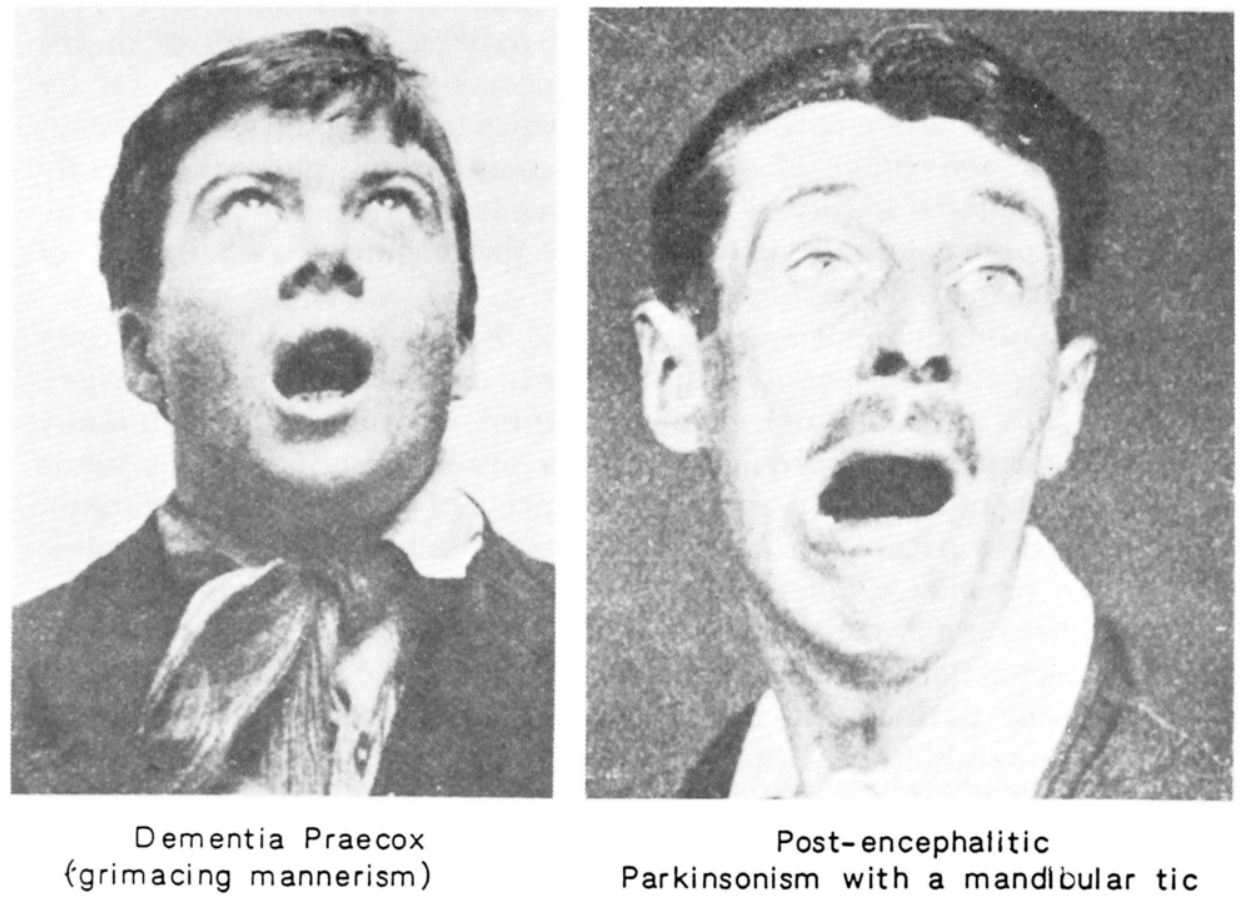

FIG. 2. Conflicting views of the same disorder-illustrations from contemporary text books (Norman, 1928; Wilson, 1940). 
The two views of the Necker Cube have also been applied to the cognitive disorders of psychiatric illness (Rogers, 1986a). This has been the subject of a considerable number of studies since the introduction of standardized methods of cognitive assessment at the beginning of this century. One of the most striking aspects of these studies, however, is the apparent contradiction between their findings and the conventional conclusions drawn from them. Almost invariably, the studies showed that psychiatric illness is associated with intellectual impairment, and that the more severe the psychiatric illness, the more severe the intellectual impairment. At its most severe, it approached the intellectual impairment associated with known cerebral disorders. Intellectual disorder however, is a hallmark of cerebral disorder. Since the prevailing paradigm did not regard psychiatric illness as cerebral disorder, intellectual disorder therefore could not form part of psychiatric illness. In 1941, for example, Brody, surveying the results of intelligence tests in patients with psychiatric disorder up to that time, concluded that in organic cases, a true dementia occurred, but that in functional disorders test failure was more often the result of "pseudodementia", that is, disturbances of cooperation. The various disorders could be ranked by test performance with psycho-neurosis performing best, manic depressive insanity next and schizophrenia least well; the severity of pseudodementia occurred in these conditions in exactly the reverse order. Subsequent studies heroically continued to attempt to differentiate the cognitive disturbance in psychiatric illness from "true" cognitive impairment. In 1978, Heaton and colleagues reviewed 94 studies between 1960 and 1975, which compared test scores of psychiatric patients with scores of braindamaged patients or with "established norms for organicity". Of 34 attempts to discriminate chronic schizophrenics from organics, the median hit rate (total percentage of organic and non-organic patients correctly classified by the tests) hardly exceeded chance level prediction at $54 \%$. The same endeavour continues to distinguish the cognitive impairment of affective disorder and dementia.

Organic and functional are weasel words. Both terms have two distinct meanings. Organic can mean anatomical or it can mean physical in origin. Functional can mean physiological, or mental in origin. The dichotomy between anatomical and physiological is a purely descriptive one, made between two complementary biological aspects of an organ or organism. When applied to pathology, it separates cases where there is recognizable macroscopic or microscopic change from cases where there is not. The dichotomy between physical and mental origin, however, represents the two different views of the Necker Cube described above. The two issues, presence of recognizable pathological change and physical or mental origin, are completely separable and bear no necessary relation to each other. Biochemical or electrical is not the same as mental. Confusion arises when these two separate dichotomies are not distinguished. The brain disorder of psychotic illnesses classified as functional has been extensively studied, but it is a study that is in danger of never bearing fruit. When, in particular cases, brain disorder is established, these are typically excluded from the study, not 
because the case has been shown not to proceed from a mental origin, but because brain disorder has been established. This preserves the psychological paradigm of psychiatric disorder, but does nothing to further our understanding of these illnesses, and in fact removes the very cases from study that have the most to tell us. Davidson and Bagley, in their extensive review of the schizophrenia-like psychoses associated with different neurological disorders (1969), concluded that in many CNS disorders, the association of "schizophrenia" exceeded chance expectation, that alleged distinguishing clinical features between these psychoses and "true" schizophrenia were largely illusory, that the site of the brain lesions appeared to be more important than the previous personality of the patient in the genesis of the psychosis, and that, in most cases, the CNS disorder appeared to be the necessary cause of the psychosis. They felt that the study of relatively rare cases, where clear neurological disorder and schizophrenia-like psychoses are associated, provides important clues to the nature of the cerebral function underlying causes of the more common cases of schizophrenia with no clear neurological disorder. Regarding schizophrenia as a neurological disorder is only gradually becoming acceptable, although all the facts necessary to establish this have long been available (Trimble and Rogers, 1987). This can only be understood in terms of a psychological paradigm for schizophrenia being prevalent for most of this century.

The conclusion of Davison and Bagley about the association of psychotic disorder and neurological disorder is probably equally true of the association of neurotic and neurological disorders (Rogers, 1988). Here again, the psychiatric Necker Cube has been in operation. In an editorial on the neuroses in 1930, it was still argued that the term neurosis indicated disturbance of function of nervous tissue as William Cullen, who coined the term in the 18th century, had intended. Restricting its use to cases where no recognizable physiological disability could be detected was criticized, and equating the absence of any recognizable physiological etymology with a psychological origin even more so. As late as 1940, a standard text book of neurology (Wilson, 1940) classified certain neurological disorders as neuroses. The alternative viewpoint, which became more and more accepted, was represented, for example, by Sief (1928), who argued that neurosis was a social disturbance-a "half and half adjustment to the tasks of life". The neurotic person was cooperative so far as his superiority was approximately guaranteed, but the moment this superiority was endangered in the face of blame, defeat, decision or responsibility, he tended to secure his self-esteem with the "alibi" of neurotic symptoms. Neurosis was acquired as the result of a mistaken estimate of self and life during childhood. Janet, in his book on obsessional disorder and psychasthenia (1903) justified the psychological viewpoint as a necessary precursor to "anatomical" thinking, since if "one should always think anatomically then one would have to resign oneself to not thinking at all when it comes to psychiatry". Once established, however, the psychological paradigm remained prevalent, despite increasing understanding of the possible neuro-physiological basis of psychiatric disorder. Indeed, it was applied to recognized neurological disorder. Jelliffe, for 
example, (1927, 1940), suggested that the drooling of saliva in postencephalitic parkinsonism represented displaced seminal emission, and the tremor of parkinsonism repressed sadism. In the 1950s, when ACTH was successfully introduced in the treatment of disorders such as rheumatoid arthritis, it precipitated psychiatric disturbance in some patients. This it was argued was due to the too rapid removal of physical symptoms which had been up till then the only means of expression for psychological tension and conflicts (Doust, 1952). As late as 1977, when Capstick and Seldrup showed a relationship between the history of abnormal birth and the later development of obsessional states, they favoured an explanation in terms of psychological factors at the time of birth. The issue is well crystallized in the overlap of Parkinson's Disease with affective disorder (Rogers, 1986b; Rogers et al., 1987).

Switches of prevailing paradigm usually occur over a 20-30-year period, as a new generation grows up with a new paradigm. Individual conversions from one paradigm to another, such as Camilla Anderson described in 1952 - "symptoms which I had looked upon in my patients for many years, and had accepted as the bizarre or stereotyped behaviour of schizophrenics, and which I had conscientiously tried to interpret psychodynamically, now increasingly appeared to me as similar, if not actually identical with known organically determined symptoms"--are rare. More common is the switching of psychiatric paradigms in the case of individual patients. A recent issue of the British Fournal of Psychiatry carried a report of two cases of depressive catatonic stupor, which are attributed to encephalitis lethargica (Johnson and Lucy, 1987), but not on the basis of any positive results on investigation. The late Richard Hunter is quoted in support of their argument. Hunter never diagnosed depression or schizophrenia in any of his patients, but encephalitis in a considerable proportion. Many of these patients had carried conventional psychiatric diagnoses before they came under his care, and after his death the same patients again resumed conventional psychiatric diagnoses, including one who had been diagnosed as having encephalitis lethargica by colleagues at the National Hospital, Queens Square. One man's depression or schizophrenia is another man's encephalitis. Bleuler himself, in the last edition of his text book of psychiatry, acknowledged that schizophrenia and epidemic encephalitis could be indistinguishable (Bleuler, 1937). The same is true of other neurological disorders. As a psychiatric houseman, I was told by one of my consultants that a patient of his on a ward of patients with chronic schizophrenia had previously been diagnosed after investigation on having cerebral lupus. However, he had forgotten which one so that all the patients had a diagnosis of schizophrenia again. I had to try and re-establish the diagnosis by performing blood tests on all the patients on the ward. In such cases the Necker Cube switches before one's eyes.

Any psychiatric or neurological disorder can be viewed from either the neurological or the psychological paradigm. Psychological interpretations of neurological disease, such as those of Jelliffe, may not be fashionable but, logically, are no less valid than psychological interpretations of psychiatric 
disorders. A paradigm cannot be refuted by particular facts, since any fact can be validly interpreted by either paradigm, just as the individual components of the Necker Cube do not change according to the way it is viewed. The only implication for treatment is that with the psychological paradigm, medical treatment is inappropriate. Neurological disorder can be precipitated, exacerbated, improved, or completely resolved by psychosocial factors (Rogers, 1987a). This is quite compatible with a neurological paradigm. Neurological and psychiatric paradigms are different ways of making sense of psychiatric disorder. Either paradigm is legitimate. What is not legitimate is to divide psychiatric disorder into two exclusive categories, neurophysiological and psychological dysfunction. These are but two views of a Necker Cube.

\section{References}

Anderson, C. M. (1952) Organic factors predisposing to schizophrenia. The Nervous Child, 10, $36-42$.

Arieti, S. (1972) Volition and value: a study based on catatonic schizophrenia. In "Moral Values and The Superego Concept in Psycho-analysis" (ed. S. C. Post). International Universities Press, New York.

Berrios, G. C. and Samuel, G. (1987) Affective disorder in the neurological patient. Journal of Nervous and Mental Disease, 175, 173-176.

Bleuler, E. (1937) "Lehrbuch der Psychiatrie" 6th Ed. Berlin. Quoted in: Hunter, R. and Macalpine, I. (1974) "Psychiatry for the Poor". Dawsons, London.

Brody, M. B. (1941) A survey of the results of intelligence tests in psychosis. British Fournal of Medical Psychology, 19, 215-261.

Brown, G. L. and Wilson, W. P. (1984) Alterations in cognitive performance and affectarousal state during fluctuations in motor function in Parkinson's disease. Fournal of Neurology, Neurosurgery and Psychiatry, 47, 454-465.

Capstick, N. and Seldrup, J. (1977) Obsessional states; a study in the relationship between abnormalities occurring at the time of birth and the subsequent development of obsessional symptoms. Acta Psychiatrica Scandanavica, 56, 427 431.

Davison, K. and Bagley, C. R. (1969) Schizophrenia-like psychoses associated with organic disorders of the central nervous system: a review of the literature. In "Current Problems in Neuropsychiatry". (ed. R. N. Herrington). British Journal of Psychiatry. Special Publication No. 4. Headley Brothers, Ashford, Kent.

Doust, J. W. L. (1952) Psychiatric aspects of somatic immunity; differential incidence of physical disease in the histories of psychiatric patients. British Journal of Sociological Medicine, 6, 49-67.

Earl, C. J. (1983) Personal Communication.

Economo, C. von (1931) Encephalitis lethargica, its sequelae and treatment. (Translated by K. O. Newman). Oxford University Press, London.

Editorial (193) The neuroses. Journal of Neurological Psychopathology, 11, 163-166.

Hart, B. (1932) Psychology and psychiatry. Proceedings of the Royal Society of Medicine, 25, 187 200.

Heaton, R. K., Baade, L. E. and Johnson, K. L. (1978) Neuropsychological test results associated with psychiatric disorders in adults. Psychological Bulletin, 85, 141 162.

Janet, P. (1903) "Les Obsessions et la Psychasthenie" Alcan, Paris.

Jelliffe, S. E. (1927) The mental pictures in schizophrenia and in epidemic encephalitis, their alliances, differences and a point of view. American Journal of Psychiatry, 6, 413-465.

Jelliffe, S. E. (1940) The parkinsonian body posture, some considerations on unconscious hostility. Psychoanalytic Review, 27, 467-479. 
Johnson, J. and Lucey, P.A. (1987) Encephalitis lethargica, a contemporary cause of catatonic stupor. A report of two cases. British Fournal of Psychiatry, 151, 550-552.

Kuhn, T. S. (1970) "The Structure of Scientific Revolutions". 2nd Ed. University of Chicago Press, Chicago.

Maudsley, H. (1873) "Body and Mind: An Enquiry into their Connection and Mutual Influence, Specially in Reference to Mental Disorders." Macmillan, London.

Norman, H.J. (1928) "Mental Disorders, a Handbook for Students and Practitioners". Livingstone, Edinburgh.

Owens, D. G. C., Johnstone, E. C. and Frith, C. D. (1982) Spontaneous involuntary disorders of movement, their prevalence, severity, and distribution in chronic schizophrenics with and without treatment with neuroleptics. Archives of General Psychiatry, 39, 452-481.

Pichot, P. (1983) "A Century of Psychiatry". Dacosta, Paris.

Rogers, D. (1985) The motor disorders of severe psychiatric illness: A conflict of paradigms. British Journal of Psychiatry, 147, 221-232.

Rogers, D. (1986a) Cognitive disturbances: real or apparent? Psychiatry in Practice, 5, 6-8.

Rogers, D. (1986b) Bradyphrenia in parkinsonism: a historical review. Psychological Medicine, 16, 257-265.

Rogers, D. (1987a) Neuropsychiatry. British Journal of Psychiatry, 150, 425-427.

Rogers, D. (1988). Neuroses and neurological disorders. In "Biological Understanding and Therapy of Neuroses". (ed. A. Prasad). CRC Press Boca Raton. In press.

Rogers, D., Lees, A. J., Smith, E., Trimble, M. and Stern, G. M. (1987) Bradyphrenia in Parkinson's Disease and psychomotor retardation in depressive illness. An experimental study. Brain, 110, 761-776.

Sief, L. (1928) Individual psychology and the treatment of neurosis. Archives of Neurology and Psychiatry, 19, 190-191.

Steck, H. (1926, 1927) Les syndromes extrapyramidaux dans les maladies mentales. Archives Suisses de Neurologie et Psychiatrie, 19, 195-233, 20, 92-136.

Steck, H. (1954) Le syndrome extrapyramidal et diencephalique au cours des traîtements au largactil et au serpasil. Annales Medico-psychologiques, 112, 737-743.

Trimble, M. R. and Rogers, D. (1987) Neurological disorder and schizophrenia. In "Handbook of Schizophrenia". Vol. 2. Neurochemistry and Neuropharmacology of Schizophrenia. (Eds F. A. Henn and L. E. DeLisi). Elsevier, Amsterdam, pp 439-465.

Wilson, S. A. K. (1940) "Neurology". Vol. 1. Edward Arnold, London. 


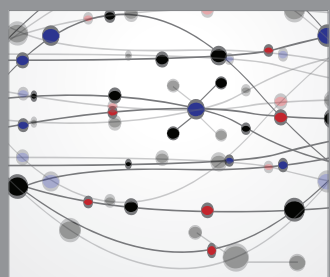

The Scientific World Journal
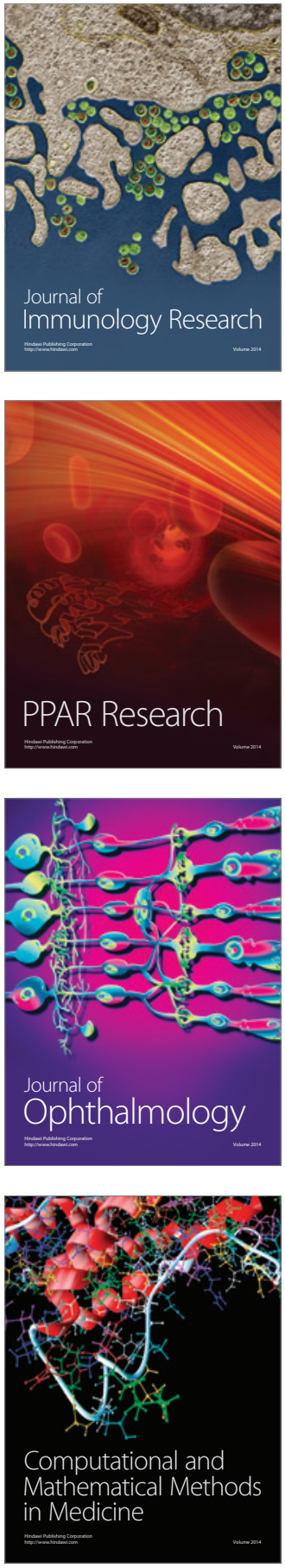

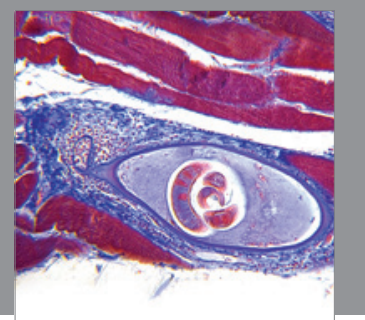

Gastroenterology

Research and Practice
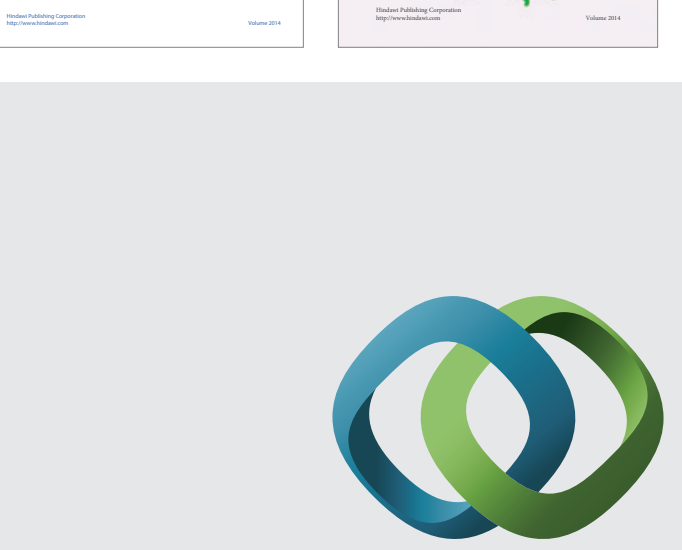

\section{Hindawi}

Submit your manuscripts at

http://www.hindawi.com
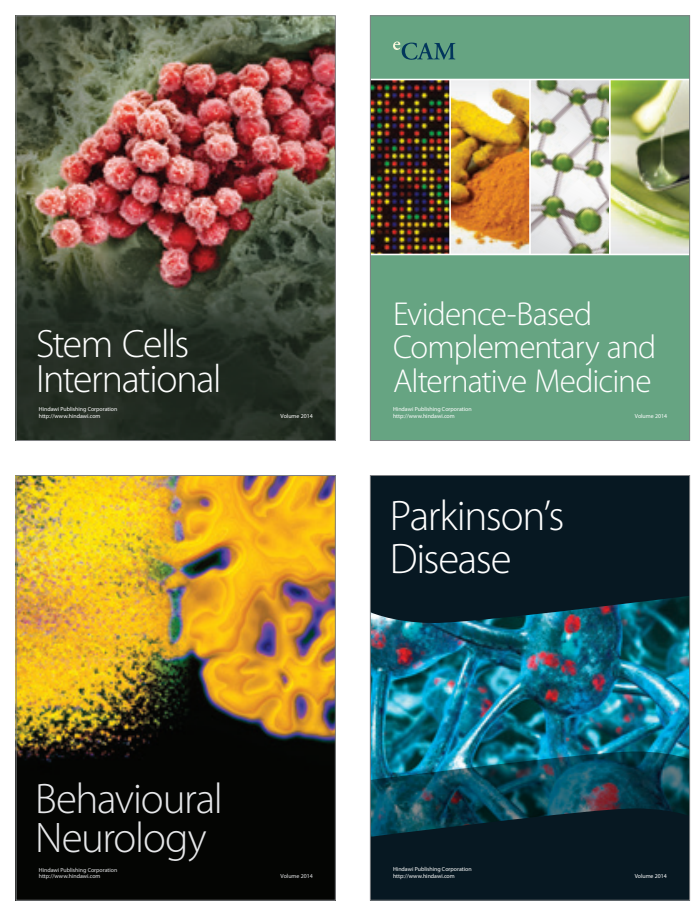

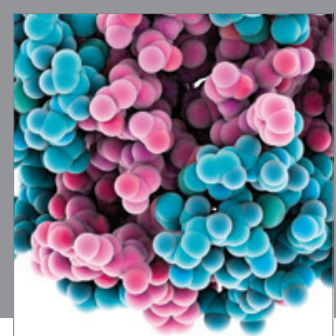

Journal of
Diabetes Research

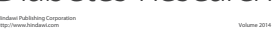

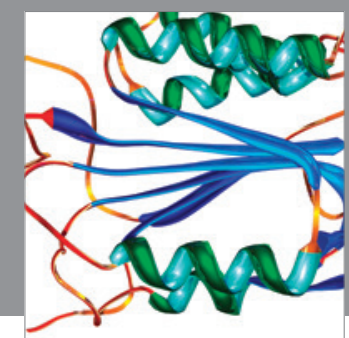

Disease Markers
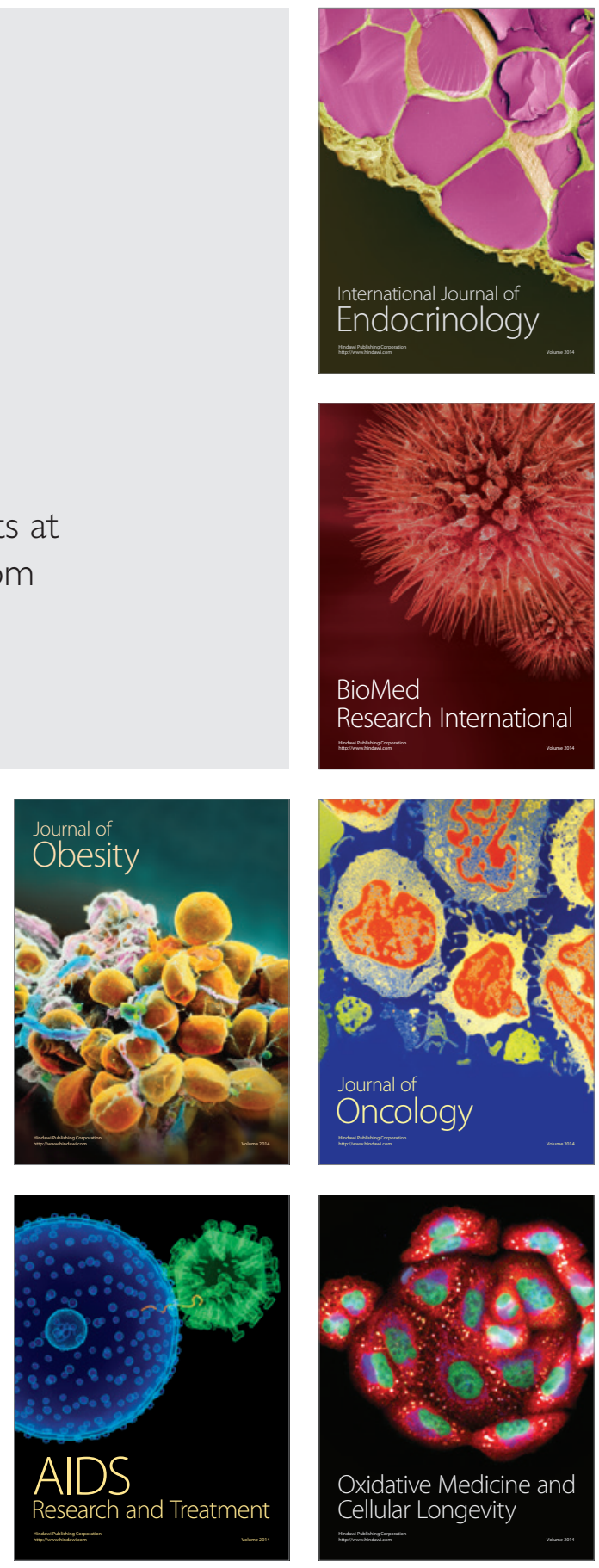